\title{
AUMENTO DA CONFIABILDADE DA PLANTA DE SÍNTER DE UMA USINA SIDERÚRGICA ATRAVÉS DA METODOLOGIA DE ANÁLISE E SOLUÇÕES DE PROBLEMAS *
}

\author{
Bruno Bermudes Crasto ${ }^{1}$ \\ Denisson Toneli De Matos ${ }^{2}$ \\ Márcio de Souza Lana ${ }^{3}$ \\ Shaney Gonçalves Mileipe ${ }^{4}$
}

\section{Resumo}

No contexto atual, os estudos de engenharia de confiabilidade se tornaram cada vez mais essenciais para o acréscimo de disponibilidade das plantas e estabilidade operacional. Este trabalho tem por objetivo, através da metodologia de análise e solução de problemas (MASP) focada em modos de falhas prioritários, reduzir o tempo de manutenção não planejada do processo de Sinterização da Arcelor Mittal Tubarão. Os resultados obtidos concretizaram um aumento de $2 \%$ na disponibilidade da planta após a elaboração de um plano para corrigir os modos de falhas críticos, revelando a importância e o potencial de ganho em se investir em estudos de confiabilidade e registro de falhas.

Palavras-chave: Confiabilidade; MASP; Análise Jack-Knife.

\section{INCREASE IN THE RELIABILITY OF THE SINTER PLANT THROUGH THE METHODOLOGY OF ANALYSIS AND PROBLEMS SOLUTION}

\section{Abstract}

In the current context, reliability engineering studies have become increasingly essential for increased plant availability and operational stability. This work aims to reduce the unplanned maintenance time of the Sintering process of the Arcelor Mittal Tubarão, through the analysis and problem solving methodology focused on priority failure modes. The results obtained achieved a $2 \%$ increase in plant availability after the elaboration of a plan to correct critical failure modes, revealing the importance and the potential gain in investing in reliability studies and failure logging.

Keywords: Reliability; MASP; Jack Knife Diagrams.

1 Engenheiro Mecânico, Engenheiro, ITC, Cobrapi, Serra, Espirito Santo, Brasil.

2 Engenheiro Eletricista, Especialista de Confiabilidade IGS, ArcelorMittal Tubarão Serra, Espirito Santo, Brasil.

3 Engenheiro Mecânico, Especialista de Confiabilidade IGS, ArcelorMittal Tubarão Serra, Espirito Santo, Brasil.

4 Engenheiro de Automação e Controle, Especialista de Manutenção e Gestão de Ativos, ITC, ArcelorMittal Tubarão Serra, Espirito Santo, Brasil.. 


\section{INTRODUÇÃO}

\subsection{Motivação}

No contexto econômico vivenciado no Brasil, cada vez mais se faz necessário que as empresas busquem a otimização de seus processos para ganhar competitividade no mercado. É de suma importância uma gestão de manutenção que assegure alta confiabilidade e disponibilidade das usinas, trazendo estabilidade operacional aliada a um potencial de redução de custos.

Diante desta necessidade, a unidade de siderurgia, Arcelor Mittal Tuburão, do grupo Arcelor Mittal, maior fornecedor mundial de aço bruto, identificou a oportunidade de desenvolver um estudo de engenharia de confiabilidade utilizando a metodologia de análise e solução de problemas (MASP) para a planta de Sinterização, visto que seu indicador de tempo de manutenção não planejada vinha nos últimos meses se distanciando da meta.

\subsection{Arcelor Mittal Tubarão e o Processo de Sinterização}

Dentro da América Latina, a ArcelorMittal Brasil, produtora de aços longos e planos, apresenta capacidade produtiva anual de 13 milhões de toneladas de aço e opera 27 unidades. O processo produtivo de aços planos inicia-se na unidade ArcelorMittal Tubarão (AMT), usina integrada localizada na região da Grande Vitória - Espírito Santo, com capacidade produtiva anual de 7,5 milhões de toneladas de aço líquido.

De maneira sucinta o fluxo produtivo da AMT, começa, conforme a figura 1, com a produção das matérias primas de coque, sínter e cal, através dos processos da Coqueria, Sinterização e Calcinação. Estas matérias primas e outras adições como pelota e minério de ferro, passam por reações químicas e de redução que ocorrem nos Altos Fornos produzindo assim o ferro gusa, principal matéria prima do aço.

Na Aciaria ocorre a transformação do ferro gusa, transportado pelos carros torpedos, em aço líquido, com a adição de alguns elementos de liga. A transformação se dá a partir do sopro de oxigênio que oxida os elementos contidos no ferro gusa e aumenta a temperatura do metal. Este aço líquido passará por beneficiamentos nos refinos primários e secundários e será resfriado de maneira controlada nas máquinas de Lingotamento Contínuo, formando assim as placas de aço.

Estas placas serão inspecionadas e tratadas na área de condicionamento de placas e assim enviadas para os clientes, ou serão destinadas para o LTQ. A laminação de tiras a quente (LTQ) transformará as placas em bobinas, que podem ou não passar pelas linhas de acabamento de bobinas antes de destinarem para os clientes. 


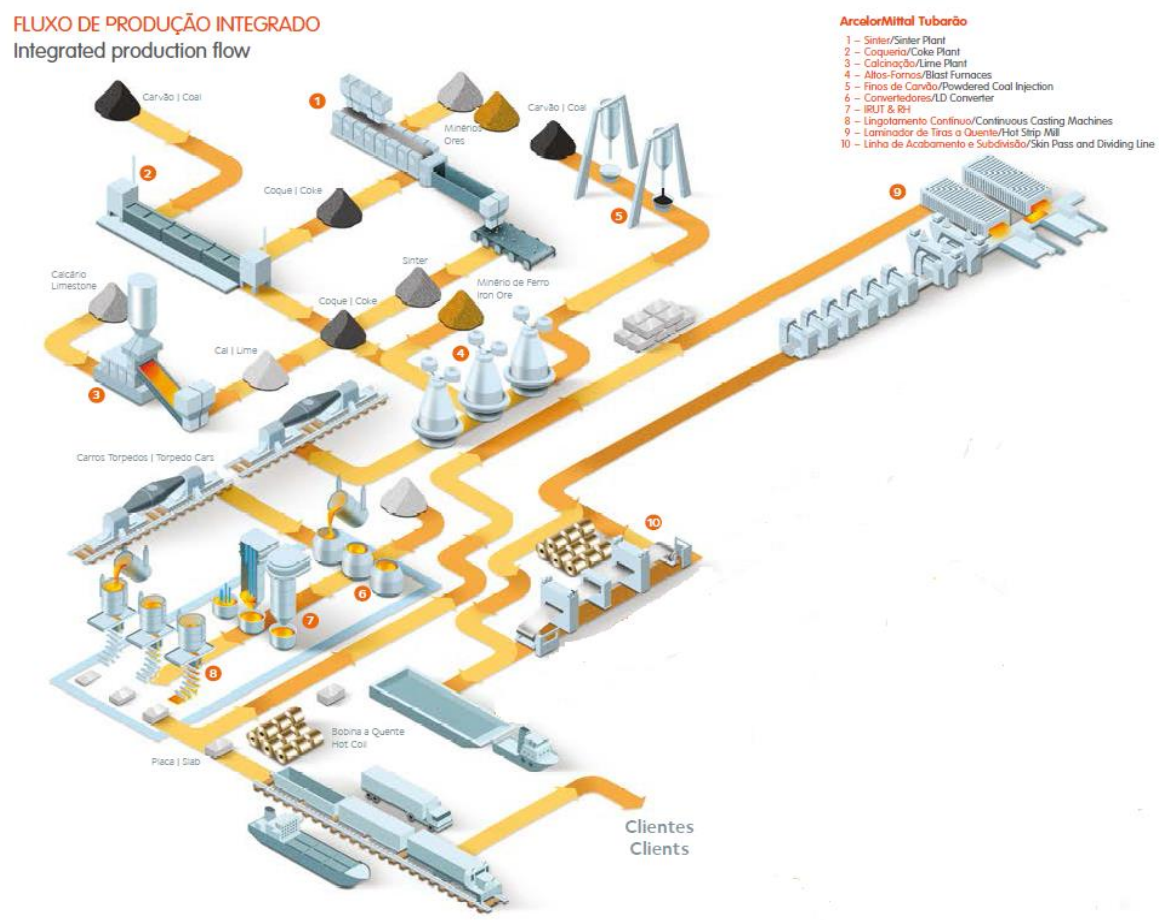

Figura 1. Fluxo processo produtivo ArcelorMittal Tubarão

A Máquina de Sinterização, objeto de estudo deste trabalho, é um equipamento de grande importância para o processo Siderúrgico adequado para pequenas ou grandes usinas, com objetivo principal de aglomeração do sínter-feed e reaproveitamento de pó oriundo dos processos subsequentes. A flexibilidade de modificação da composição química do produto sínter se sobressai em releção à pelota do minério de ferro (produto oriundo do pellet-feed), propiciando assim correção do balanço físico-químico nos Altos Fornos. É usado como autofoundente, com boas propriedades físico-químicas e metalúrgicas.

O processo consiste em misturar e homogeneizar finos de minérios, finos de carvão ou coque, finos de fundentes, umidade, e fazer a combustão do carvão ou coque de modo que a temperatura atinja 1200 a $1400^{\circ} \mathrm{C}$, condição suficiente para que a umidade evapore e as partículas da carga se unam por caldeamento, obtendo-se um material resistente e poroso denominado sínter.

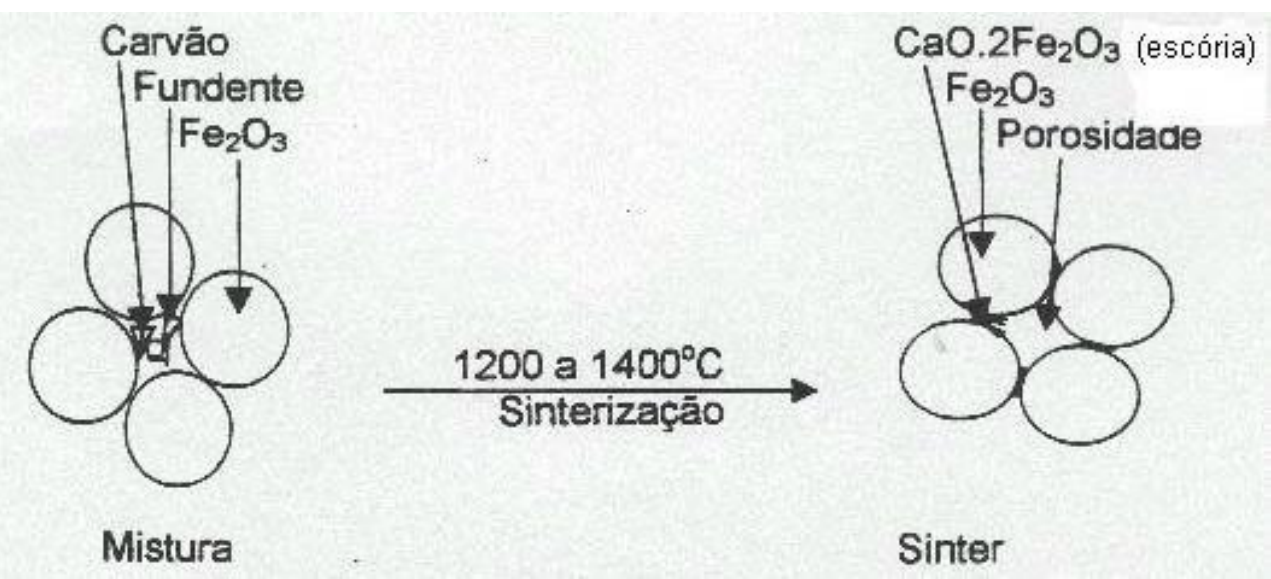

Figura 2. Esquema do Princípio da Sinterização 
A mistura homogeneizada é transportada por carros grelhas que compõe a esteira da Máquina de Sinterização, e, ao longo da extensão ocorre o processo de caldeamento entre os finos. Logo, o sínter produto é descarregado e fragmentado para alcançar granulometria maior que $5 \mathrm{~mm}$ menor que $50 \mathrm{~mm}$. A fração menor que $5 \mathrm{~mm}$ retorna para o processo de sinterização.

O material, já na forma de sínter, é direcionado para o equipamento Resfriador a uma temperatura de $800^{\circ} \mathrm{C}$ e resfriado para uma temperatura de $130^{\circ} \mathrm{C}$ na descarga do Resfriador. O resfriamento ocorre através do sopro do ar atmosférico por cinco ventiladores. $O$ ar permeia por debaixo do grelhado do carro do Resfriador, ocorrendo assim a troca de calor entre 0 ar e a massa sinterizada. Após resfriamento o sínter produto é enviado diretamente para os Altos Fornos na forma de carga metálica para a produção do ferro gusa.

\subsection{Objetivo}

Este trabalho tem como objetivo aumentar a confiabilidade da planta de Sinterização da Arcelor Mittal Tubarão, através da metodologia de análise e solução de problemas (MASP) focada em modos de falhas prioritários, além de alcançar estabilidade dos equipamentos e redução do indicador de tempo de manutenção não planejada do processo de Sinterização, de modo a reduzir variabilidade na carga metálica dos Altos Fornos.

\subsection{Revisão Bibliográfica}

\subsubsection{MASP}

O método de Análise e Solução de Problemas (MASP) consiste numa metodologia estruturada que visa solucionar problemas complexos em processos, produtos ou serviços de organizações.

O MASP é um caminho ordenado, composto previamente de passos e sub-passos para a escolha do problema, análise de suas causas, planejamento e consolidação de um conjunto de ações para solucionar o problema, verificação dos resultados e realimentação do processo para a consolidação do aprendizado e aplicação em novos estudos.

Os passos do MASP, são:

- Identificação do Problema: Definir e reconhecer a importância do problema;

- Observação: Levantar, com ampla visão, características específicas;

- Análise: Identificar causas;

- Plano de Ação: Planejar ações com intuito de cessar as causas;

- Ação: Executar as ações;

- Verificação: Verificar eficácia do plano de ação;

- Padronização: Prevenir o reaparecimento de problemas com a mesma natureza;

- Conclusão: Auxiliar soluções para trabalhos futuros. 


\subsubsection{Gemba}

O termo Genchi Genbutsu ou Gemba, como também é muito conhecido, significa literalmente peça ou lugar verdadeiro. Teve origem na indústria Toyota, que incentivava seus funcionários a saírem de seus escritórios para solucionarem seus problemas no campo.

Descreve a ação de ir até um local para verificar uma situação real com o objetivo de entender profundamente o que aconteceu. Estar no local em que o problema ocorreu possibilitará uma visão particular, além da obtenção de importantes informações adicionais que solidificarão e fundamentarão o processo decisivo.

\subsubsection{Análise Jack-Knife}

A análise Jack-Knife, desenvolvida por Peter F. Knights, consiste em plotar um gráfico de dispersão utilizando-se dados de falhas conforme figura 3 , no qual os eixos, MTTR (mean time to repair) e frequência de ocorrência, estão na base logarítmica para linearizar a disponibilidade, e assim auxiliar processos decisórios para estratégias de manutenção.

O princípio de priorização baseia-se em classificar as falhas em AGUDAS e CRÔNICAS, dividindo o gráfico em quadrantes.

- O quadrante na esquerda superior representa as falhas agudas aonde há um alto tempo de reparo, indicando assim um possível problema de mantenabilidade;

- O quadrante da direita inferior representa falhas crônicas, com alto índice de reincidência, logo problemas de confiabilidade;

- O quadrante na direita superior, representa as falhas crônicas agudas que se repetem e que demandam um alto tempo de manutenção.

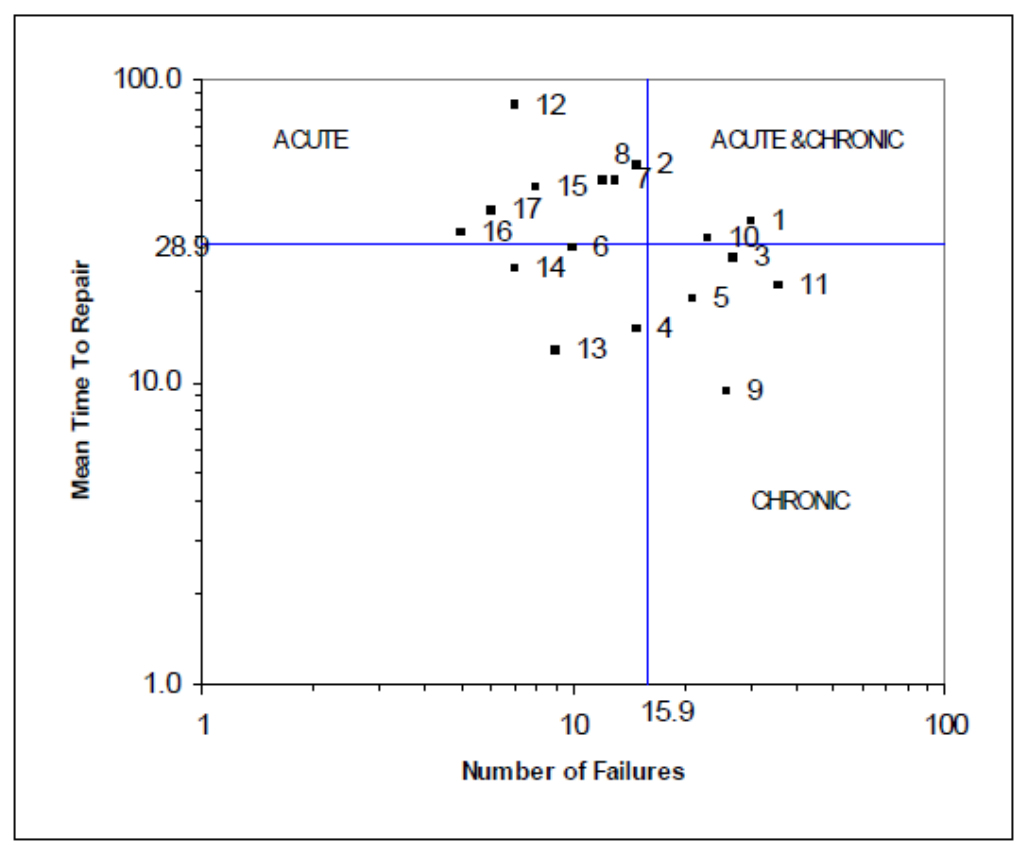

Figura 3. Gráfico de dispersão Jack-Knife 
A direita da linha vermelha conforme figura 4, podemos identificar as falhas que representam $80 \%$ do impacto na disponibilidade da planta tornando-se os objetos em evidencia.

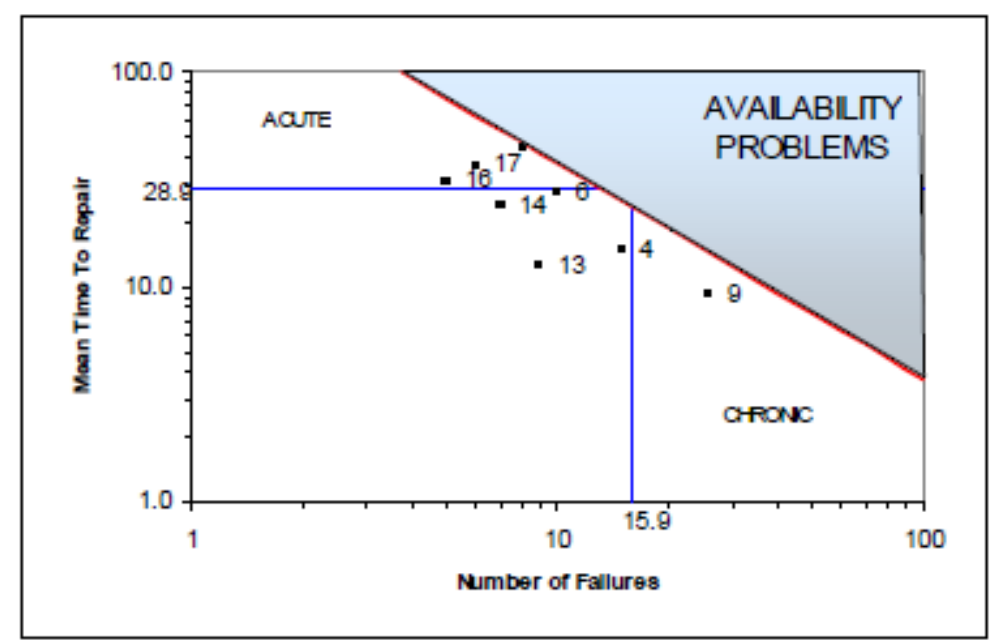

Figura 4. Identificação de falhas críticas

\subsubsection{Mapas Mentais}

Mapa mental é um diagrama sistematizado pelo psicólogo Tony Buzan, com intuito de auxiliar a gestão do conhecimento e muito utilizado na gestão estratégica de organizações.

No contexto da manutenção, é um excelente recurso para representar o relacionamento entre informações que podem estar fragmentadas e pulverizadas no ambiente industrial, possibilitando com que causas e efeitos das falhas dos equipamentos se tornem mais palpáveis e claras.

\subsubsection{Porquês}

O método dos 5 porquês consiste num processo simples de resolução de problemas com foco nas causas e não nos sintomas, e que ao mesmo tempo apresenta potencial de gerar excelentes resultados, no qual através de 5 perguntas 'porquês', possibilita identificar a causa raiz de um problema.

A simplicidade da técnica proporciona grande flexibilidade e permite aderência com outras técnicas, como por exemplo os mapas mentais. 


\section{MATERIAIS E MÉTODOS}

Com o intuito de aumentar a Confiabilidade da planta de Sínter utilizou-se para este trabalho a Metodologia de Análise e Soluções de Problemas (MASP), além de outras ferramentas de qualidade e confiabilidade.

$\mathrm{Na}$ etapa de 'Identificação do problema', etapa crucial deste trabalho, foram utilizadas as ferramentas de Gemba, Análise de Jack-Knife e Mapas Mentais. A ferramenta de Gemba teve como objetivo estabelecer um primeiro contato com a planta produtiva através de uma visita técnica, e assim nortear o desenvolvimento do objeto deste trabalho. Posteriormente, levantaram-se os dados de falha da Sinterização, através do CMMS, e realizou-se uma análise de Jack-Knife com intuito de identificar quantitativamente os maiores e principais responsáveis pela indisponibilidade da planta. A partir dos dados da Análise de Jack-Knife pôde-se definir a melhor estratégia de atuação para cada equipamento, sendo que aquele que apresentou maior impacto no diagrama foi escolhido para prosseguimento deste trabalho e tornou-se objeto de um Mapa Mental.

$\mathrm{Na}$ etapa de 'observação' utilizou-se novamente a metodologia de Gemba em conjunto com um Brainstorming, com intuito de visitar a área operacional e validar os dados de falha extraídos pelo CMMS, através de um processo de elicitação com o corpo técnico responsável pelo processo de Sinterização.

O passo seguinte, na 'análise' do problema, utilizou-se o método dos 5 Porquês com a finalidade de descobrir a causa raiz das falhas e assim elaborou-se o "plano de ação' com auxílio da ferramenta 5W2H.

Após a execução do plano de ação realizou-se uma visita técnica na área e coletouse novos dados de falha, os quais foram destinados para uma análise de Jack-Knife, na qual pode-se 'verificar' a eficácia do plano de ação. Elaborou-se padrões e documentações para a erradicação definitiva dos problemas e aqueles remanescentes passaram por nova análise completando assim o ciclo do PDCA. Um resumo de toda a metodologia utilizada neste trabalho é apresentado na tabela 1. 
Tabela 1. Metodologia e Ferramentas utilizadas

\begin{tabular}{|c|c|c|c|}
\hline \multicolumn{4}{|c|}{ MASP } \\
\hline Metodologia & Passos & Ferramentas & O que \\
\hline \multirow{7}{*}{$\mathbf{P}$} & \multirow{4}{*}{1 - Identificação } & Gemba & $\begin{array}{l}\text { Visita a área (conhecer o } \\
\text { equipamento) }\end{array}$ \\
\hline & & \multirow{2}{*}{ Jack-Knife } & Levantamento de dados \\
\hline & & & Elaboração do Jack Knife \\
\hline & & Mapa Mental & $\begin{array}{l}\text { Criar mapa mental com os dados do } \\
\text { Jack-Knife }\end{array}$ \\
\hline & \multirow[b]{2}{*}{2 - Observação } & Gemba & $\begin{array}{l}\text { Visita a área (conferencia dos dados } \\
\text { coletados - CMMs) }\end{array}$ \\
\hline & & Brainstorming & $\begin{array}{l}\text { Conferencia de dados registrados } \\
\text { com informações elicitadas }\end{array}$ \\
\hline & 3 - Análise & 5 Porquês & Achar causa raiz \\
\hline \multirow{2}{*}{ D } & 4 - Plano de ação & $5 \mathrm{~W} 2 \mathrm{H}$ & Criar Plano de ação \\
\hline & 5 - Ação & $5 \mathrm{~W} 2 \mathrm{H}$ & Executar Plano de ação \\
\hline \multirow{4}{*}{ C } & \multirow{4}{*}{6 - Verificação } & \multirow{2}{*}{ Gemba } & Visita a área \\
\hline & & & Levantamento de dados \\
\hline & & \multirow[b]{2}{*}{ Jack-Knife } & Elaboração de um novo Jack Knife \\
\hline & & & $\begin{array}{l}\text { Comparar dados de falhas antigos } \\
\text { com os novos e medir } \\
\text { disponibilidade }\end{array}$ \\
\hline \multirow[b]{2}{*}{$\mathbf{A}$} & 7 - Padronização & Padrões Lean & $\begin{array}{l}\text { Elaboração ou alteração de } \\
\text { documentos, treinamentos e } \\
\text { comunicação. }\end{array}$ \\
\hline & 8 - Conclusão & $5 \mathrm{~W} 2 \mathrm{H}$ & $\begin{array}{l}\text { Identificação dos problemas } \\
\text { remanescentes. Planejamento das } \\
\text { ações anti-reincidência. Balanço do } \\
\text { aprendizado }\end{array}$ \\
\hline
\end{tabular}

\section{RESULTADOS E DISCUSSÃO}

$\mathrm{Na}$ etapa de identificação do problema, aplicando a metodologia descrita anteriormente e com os dados de falhas apurados do processo de sinterização ao longo do ano de 2016, foi construído o diagrama Jack-Knife, apresentado na figura 5 abaixo.

O diagrama Jack-kinife foi usado de forma a priorizar e direcionar as ações a serem tomadas para cada tipo de problema.

Foi criado um mapa mental para os equipamentos em evidência, aqueles que representam $80 \%$ do impacto na disponibilidade da planta, apresentado na figura 6 , 
no qual para os equipamentos localizados no quadrante amarelo, adotou-se como melhor estratégia as análises de falhas pontuais, enquanto os equipamentos nos quadrantes vermelho e azul passariam pelo método MASP.

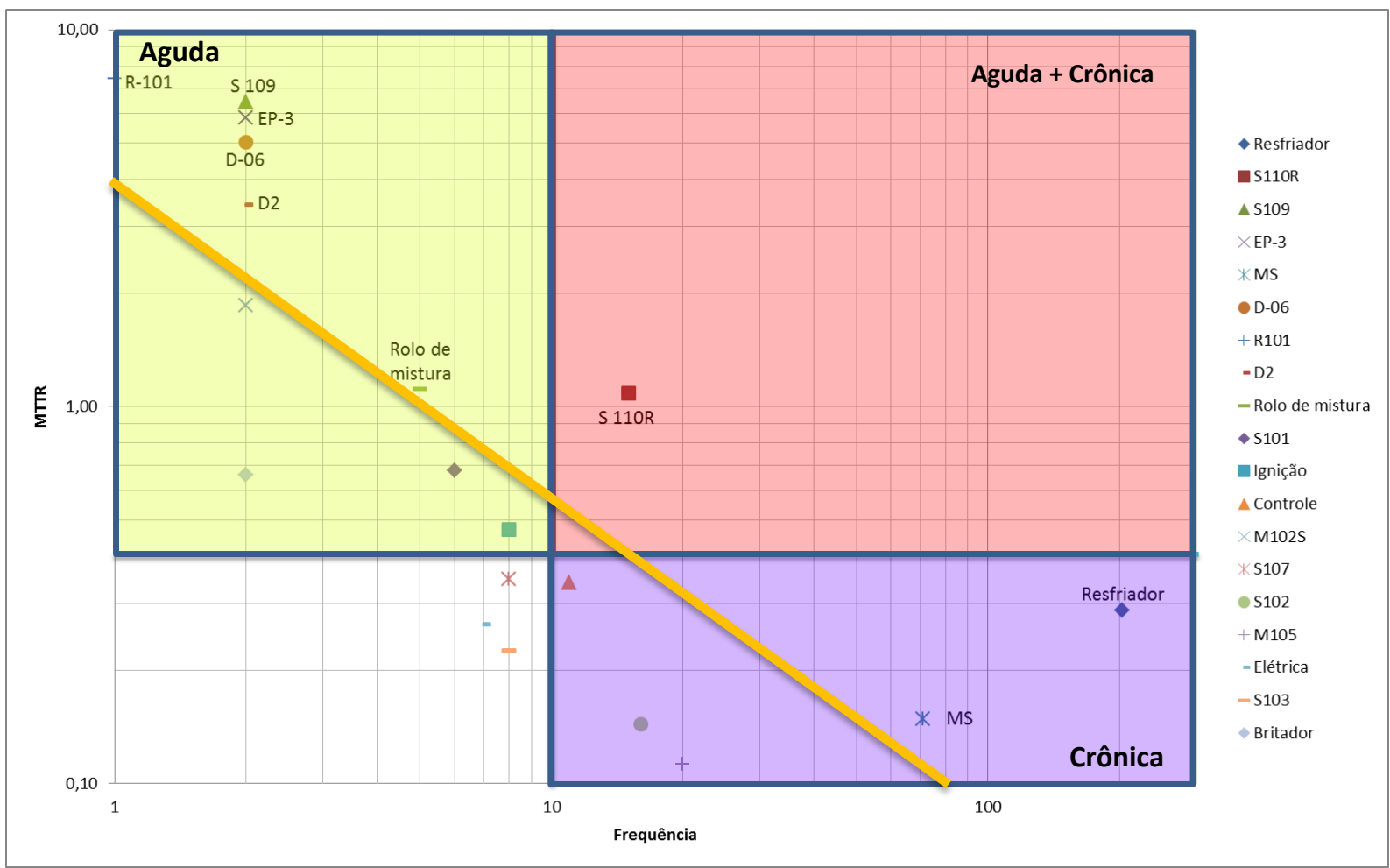

Figura 5. Análise Jack-Knife Sinterização

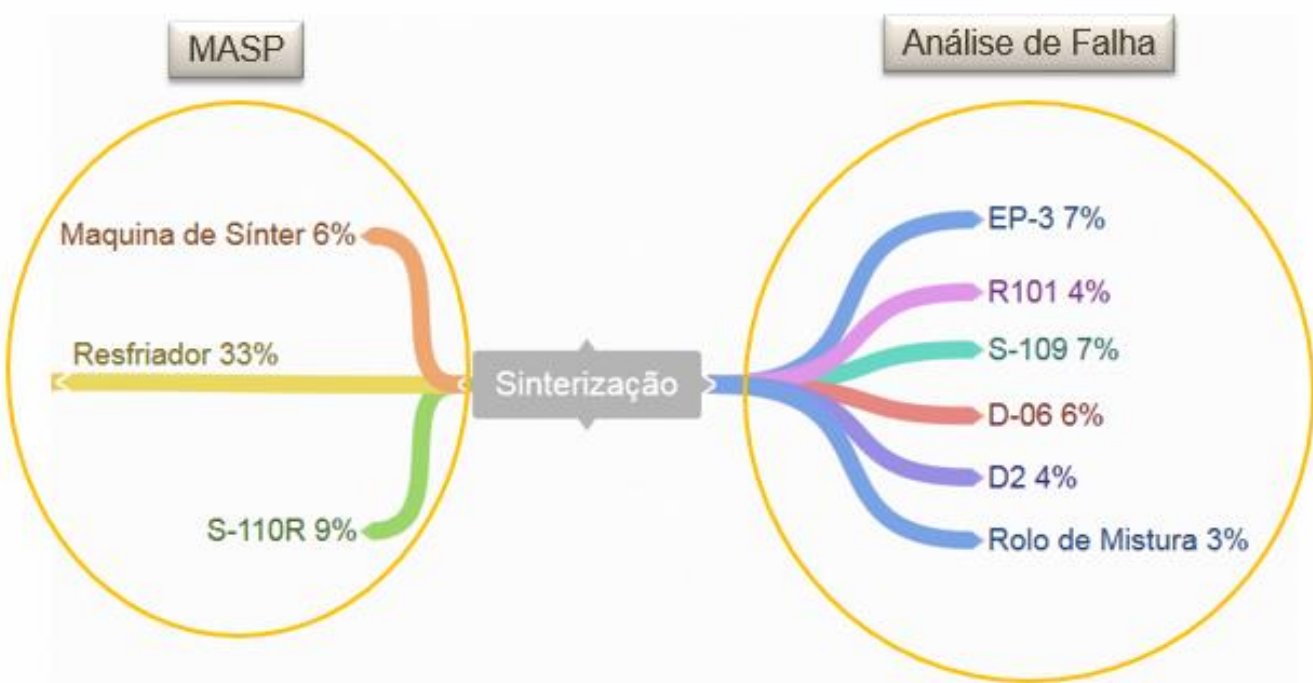

Figura 6. Mapa Mental e Melhor estratégia de Estudo de Confiabilidade 
Devido ao alto percentual de impacto na disponibilidade da Sinterização, o Resfriador foi selecionado como objeto de estudo deste trabalho. Sendo assim, elaborou-se uma análise Jack-Knife mais detalhada dos dados de falhas dos seus respectivos componentes. A análise é apresentada na figura 7 .

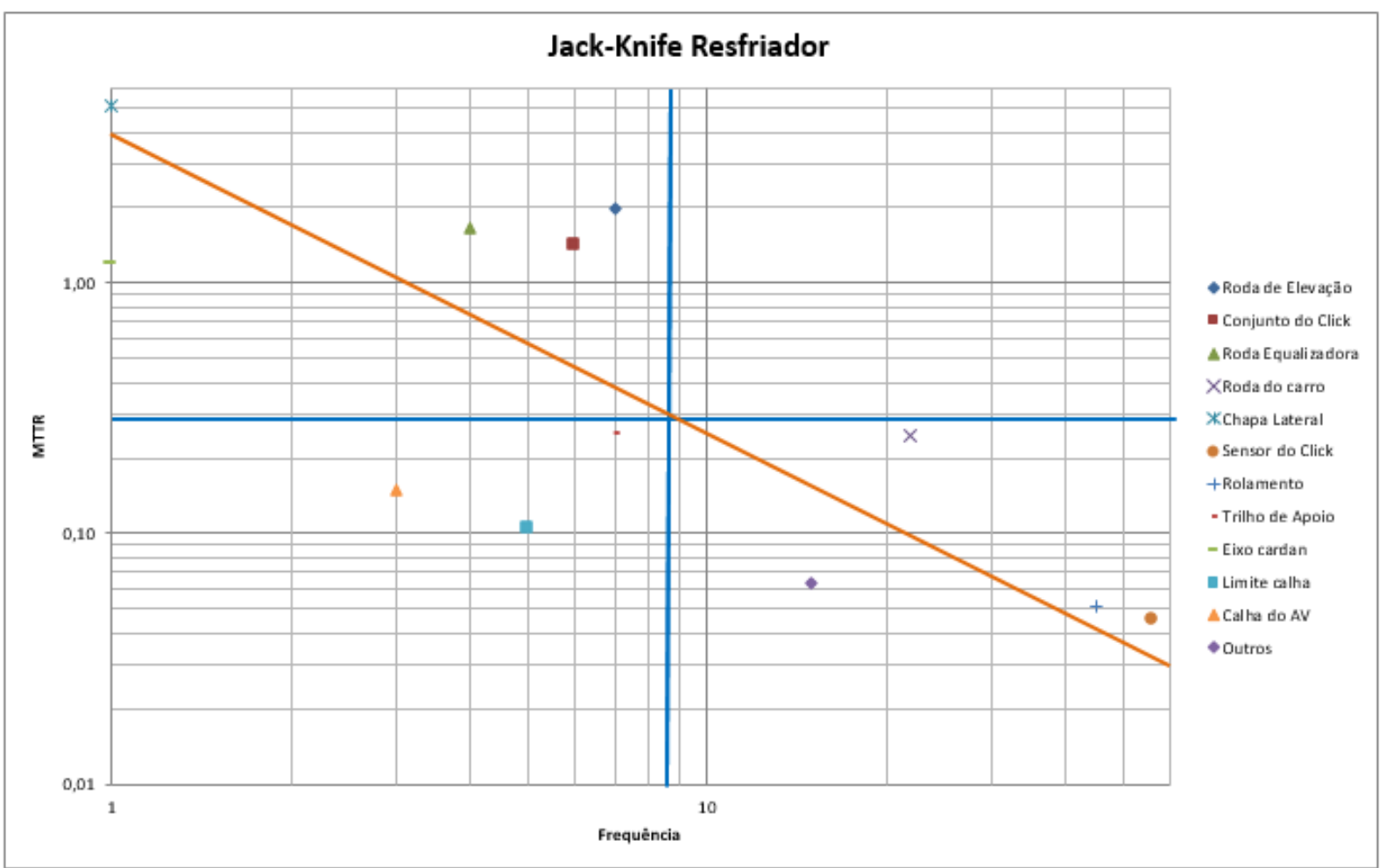

Figura 7. Análise Jack-Knife Resfriador de Sínter

Os componentes do Resfriador que apresentaram maior índice de falhas foram representados no mapa mental abaixo conforme figura 8.

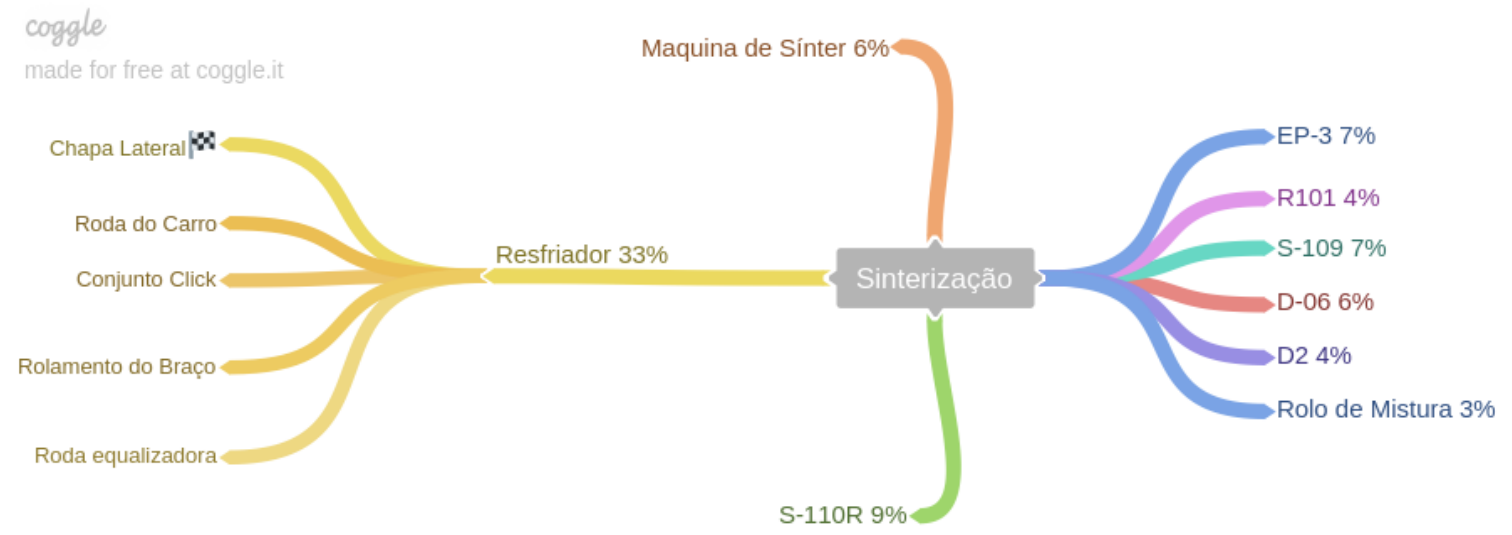

Figura 8. Mapa Mental Sinterização e Resfriador 
Tendo definido claramente os componentes do resfriador que apresentaram maior índices de falha e após validação dos dados com o corpo técnico, utilizou-se a metodologia dos 5 porquês para identificar as causas raízes das falhas de cada componente do resfriador. $\mathrm{O}$ fluxo dos 5 porquês foi representado em Mapa Mental, conforme figura 9.

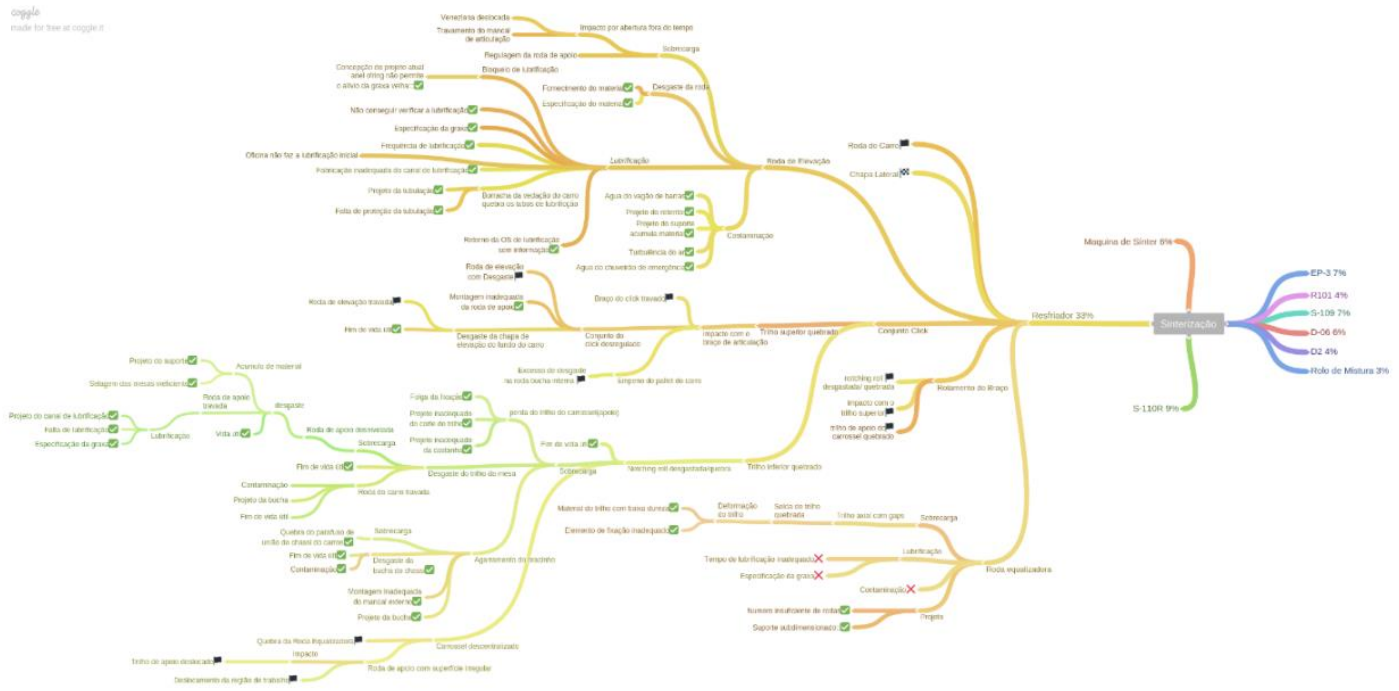

Figura 9. Mapa Mental com 5 porquês dos componentes do Resfriador

Em cima de cada causa raiz foram gerados planos de ações e após os 4 primeiros meses do ano de 2017, com um novo levantamento de dados de falha para área da Sinterização possibilitou a verificação da efetividade dos planos de ações gerados. Uma nova análise de Jack-Knife gerou o resultado apresentado na figura 10 abaixo.

Pode-se observar pelo deslocamento da posição do Resfriador que ocorreu uma grande diminuição das ocorrências de falhas. O impacto desse aspecto no processo de Sinterização como um todo, é representado pela diminuição do indicador de tempo de manutenção não planejada, como mostra a figura 11.

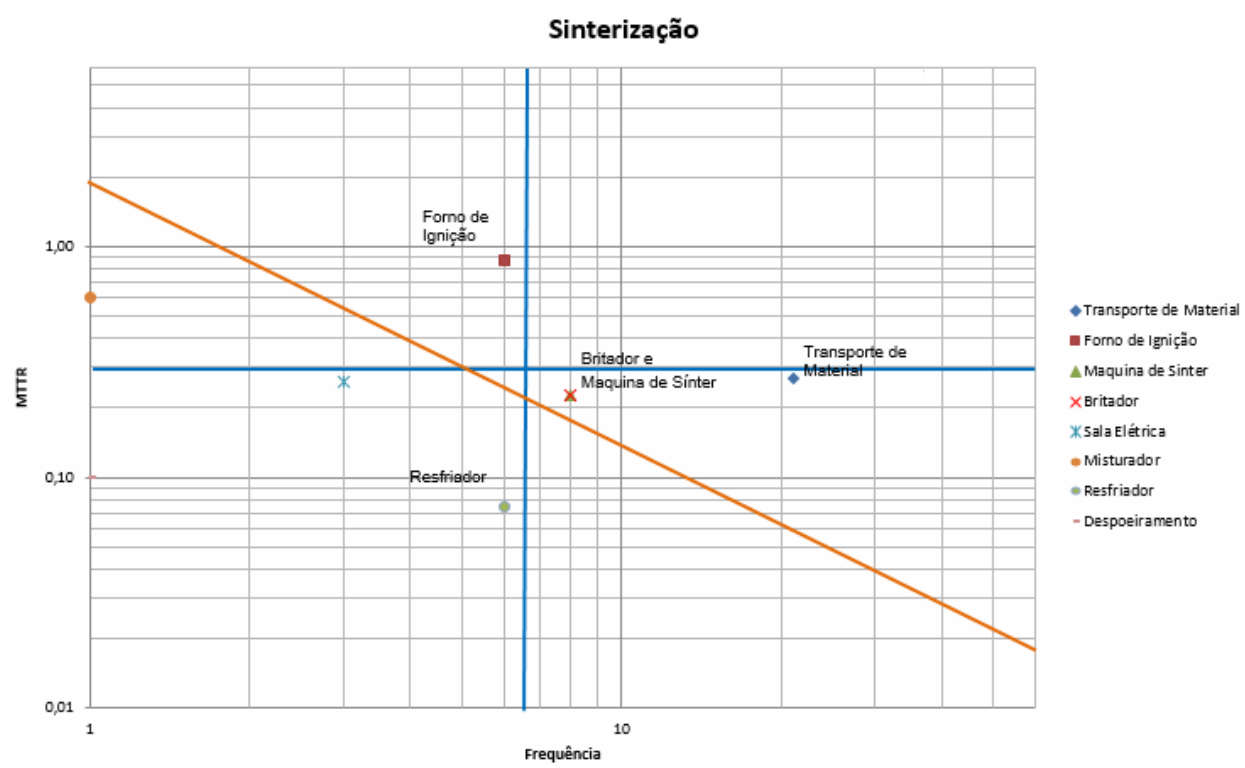

Figura 10. Análise Jack-Knife Sinterização após os planos de ação 


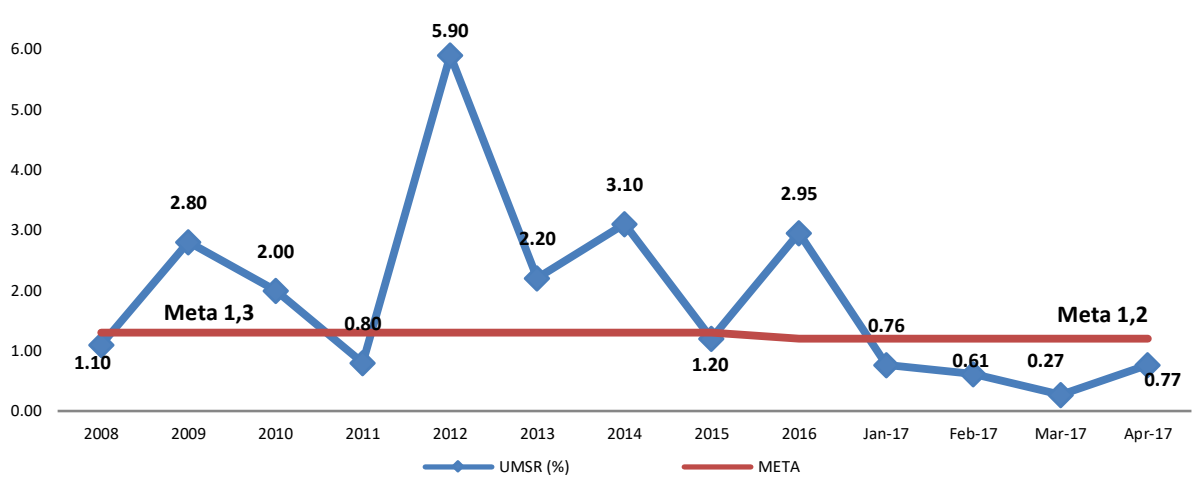

Figura 11. Taxa de tempo de manutenção não planejada da Sinterização

\section{CONCLUSÃo}

Pode-se concluir com este trabalho que a metodologia de análise e soluções de problemas utilizada obteve uma grande redução do tempo de manutenção não planejada da planta de sinterização da Arcelor Mittal Tubarão, visto que nos 4 primeiros meses do ano de 2017 este indicador ficou abaixo da meta, permitindo uma melhor estabilidade operacional.

Esta redução representou um aumento médio de $2 \%$ de disponibilidade.

Finalmente, percebe-se que através de um grande esforço para com precisão registrar falhas e anomalias, ou seja, uma boa gestão de manutenção aliada a técnicas e ferramentas de confiabilidade quantitativas e qualitativas quando bem aplicadas, podem alavancar grandes ganho, justificando investimentos neste setor.

\section{REFERÊNCIAS}

1 Knights, Peter F. Downtime Priorites, Jack-Knife Diagrams, and the Business Cycle. 2004;17(2): 14-21.

2 Morgan, J. M. e Liker, J. K. Sistema Toyota de Desenvolvimento de Produto. São Paulo: Bookman 2008.

3 Vicente, Falconi Campos TQC Controle da Qualidade Total no Estilo Japonês 2014 9a Ed.. 